\title{
Crystal structure of carbonic anhydrase CaNce103p from the pathogenic yeast Candida albicans
}

\author{
Jiř́ Dostál ${ }^{1}$, Jiř́ Brynda', Jan Blaha1', Stanislav Macháček', Olga Heidingsfeld ${ }^{1,2}$ and Iva Pichovál* (D)
}

\begin{abstract}
Background: The pathogenic yeast Candida albicans can proliferate in environments with different carbon dioxide concentrations thanks to the carbonic anhydrase CaNce103p, which accelerates spontaneous conversion of carbon dioxide to bicarbonate and vice versa. Without functional CaNce103p, C. albicans cannot survive in atmospheric air. CaNce103p falls into the $\beta$-carbonic anhydrase class, along with its ortholog ScNce103p from Saccharomyces cerevisiae. The crystal structure of CaNce103p is of interest because this enzyme is a potential target for surface disinfectants.
\end{abstract}

Results: Recombinant CaNce103p was prepared in E. coli, and its crystal structure was determined at $2.2 \AA$ resolution. CaNce103p forms a homotetramer organized as a dimer of dimers, in which the dimerization and tetramerization surfaces are perpendicular. Although the physiological role of CaNce103p is similar to that of ScNce103p from baker's yeast, on the structural level it more closely resembles carbonic anhydrase from the saprophytic fungus Sordaria macrospora, which is also tetrameric. Dimerization is mediated by two helices in the $\mathrm{N}$-terminal domain of the subunits. The N-terminus of CaNce103p is flexible, and crystals were obtained only upon truncation of the first 29 amino acids. Analysis of CaNce103p variants truncated by 29, 48 and 61 amino acids showed that residues 30-48 are essential for dimerization. Each subunit contains a zinc atom in the active site and displays features characteristic of type I $\beta$-carbonic anhydrases. Zinc is tetrahedrally coordinated by one histidine residue, two cysteine residues and a molecule of $\beta$-mercaptoethanol originating from the crystallization buffer. The active sites are accessible via substrate tunnels, which are slightly longer and narrower than those observed in other fungal carbonic anhydrases.

Conclusions: CaNce103p is a $\beta$-class homotetrameric metalloenzyme composed of two homodimers. Its structure closely resembles those of other $\beta$-type carbonic anhydrases, in particular CAS1 from Sordaria macrospora. The main differences occur in the N-terminal part and the substrate tunnel. Detailed knowledge of the CaNce103p structure and the properties of the substrate tunnel in particular will facilitate design of selective inhibitors of this enzyme.

Keywords: Carbonic anhydrase, Candida albicans, Crystal structure, CaNce103p, Substrate tunnel

\section{Background}

Carbonic anhydrases (CAs) catalyze the interconversion of carbon dioxide and bicarbonate. While the reaction $\mathrm{CO}_{2}+\mathrm{H}_{2} \mathrm{O} \leftrightarrow \mathrm{HCO}_{3}^{-}+\mathrm{H}^{+}$proceeds spontaneously, tight control of this process is so important that CAs evolved in all kingdoms of life and arose independently several times during evolution. CAs are a group of

\footnotetext{
* Correspondence: iva.pichova@uochb.cas.cz

${ }^{1}$ Institute of Organic Chemistry and Biochemistry of the Czech Academy of

Sciences, Flemingovo náměstí 2, 16610 Prague, Czech Republic

Full list of author information is available at the end of the article
}

structurally unrelated enzymes that share the same catalytic mechanism and can accelerate the spontaneous reaction up to 10,000-fold. Thus, CAs rank among the most efficient enzymes known, with catalytic efficiency approaching the diffusion-control limit [1, 2]. All CAs are metalloenzymes, most often containing zinc coordinated in a tetrahedral geometry by three amino acid residues and a hydroxyl anion. The catalytic mechanism relies on a metal hydroxide derivative formed by water and the metal ion that acts as a strong nucleophile. This

(c) The Author(s). 2018 Open Access This article is distributed under the terms of the Creative Commons Attribution 4.0 International License (http://creativecommons.org/licenses/by/4.0/), which permits unrestricted use, distribution, and 
nucleophilic species attacks the $\mathrm{CO}_{2}$ molecule bound in the active site cavity $[3,4]$.

Based on sequence and structural features, CAs can be divided into six categories: $\alpha, \beta, \gamma, \delta, \zeta$ and $\eta$ [4]. The best-studied group, the $\alpha$-class CAs, were first discovered in vertebrate erythrocytes and later found in prokaryotes, protozoa and plants $[4,5]$. $\beta$-CAs were first discovered in red clover and fern chloroplasts [6], and their presence has been reported in all other types of organisms except for mammals. Both $\alpha$ and $\beta$-CAs have been found in fungi, and all yeast CAs characterized to date belong to the $\beta$-class [3].

$\beta$-CAs are active as homodimers or higher oligomers formed by these homodimers, with one zinc atom per monomeric subunit $[4,7]$. Of the four yeast CAs that have been structurally characterized, two-those from Saccharomyces cerevisiae and Cryptococcus neoformans-have a dimeric structure. Structures of two CA isoenzymes from Sordaria macrospora display tetrameric organization [8].

Candida albicans, the most common human fungal pathogen, possesses at least one gene encoding a CA [9]. This gene has been denominated NCE103 because of its homology to S. cerevisiae gene NCE103 (non-classical export). ScNCE103 was first identified as a coding sequence for a protein detected in the extracellular space, although it lacks the classical signal peptide [10]. The protein product, ScNce103p, was later found to have CA activity and is particularly important for yeast cells in environments with low $\mathrm{CO}_{2}$ concentrations $[11,12]$.

Compared with non-pathogenic yeasts, $C$. albicans can proliferate in a more diverse range of environments. It can thrive on host skin, mucosa or blood, and it can survive on abiotic surfaces [13]. These sites differ in composition, accessibility of nutrients, $\mathrm{pH}$, and concentration of gases. The $\mathrm{CO}_{2}$ concentration in human blood is 150 -fold higher than in atmospheric air, and C. albicans can adapt to both. CA is crucial for this adaptation. C. albicans lacking both NCE103 alleles is not viable in atmospheric air. Conversely, in the presence of $5.5 \% \mathrm{CO}_{2}, \mathrm{NCE} 103$ expression was nearly undetectable $[9,14]$.

The indispensability of Nce103p, along with the fact that it is structurally unrelated to mammalian CAs, makes it a promising target for the design of novel antimycotics. Nce103p inhibitors would not act against systemic mycoses because blood contains at least $5 \% \mathrm{CO}_{2}$, which strongly downregulates NCE103. Nevertheless, such inhibitors could serve as components of ointments for topical treatment or surface disinfectants, which may be of particular use in a hospital environment. Nosocomially transmitted infections by Candida species represent a serious public health problem, and C. albicans infections are associated with high mortality rates, particularly in immunocompromised patients. The structure of CaNce103p from C. albicans presented here may facilitate the design and development of such antifungal compounds.

\section{Results \\ Cloning, expression, purification and activity detection of CaNce103p and its truncated versions}

To isolate a sufficient amount of CaNce103p for structural studies and facilitate preparation of CaNce103p variants, we developed a recombinant expression system in E. coli. The vector pET22b-wtNCE103 was constructed by inserting the CaNce103p coding sequence into a pET22b vector from which the pelB signal sequence for periplasmic localization had been removed. The stop codon at the end of the coding sequence was preserved to prevent attachment of a His-tag to the resulting protein. Four histidine residues naturally occurring at the C-terminus of CaNce103p were sufficient to enable purification using affinity chromatography on a column charged with $\mathrm{Ni}^{2+}$ cations.

Truncated versions of CaNce103p were prepared to facilitate crystallization. ScNce103p, the homologous CA from S. cerevisiae, was successfully crystallized only upon removal of the first 13 amino acids, which are not conserved among $\beta$-CAs [15]. The non-conserved $\mathrm{N}$-terminal part of CaNce103p is even longer than that of ScNce103p (Fig. 1). The vectors pET22b- $\Delta 29$ CaNCE103, pET22b- $\triangle 48$ CaNCE103 and pET22b$\triangle 61$ CaNCE103 were prepared to express C. albicans CA lacking the first 29, 48 and 61 amino acids, respectively.

Truncation by 29 and 61 amino acids was based on secondary structure prediction performed using the program CFSSP [17] (Fig. 1). Deletion of the first 29 residues removes the entire helix predicted to occur at the $\mathrm{N}$-terminus. Deletion of 61 residues removes all the residues before the beginning of the next predicted helix (Fig. 1). Deletion of the first 48 amino acids was motivated by multiple sequence alignment of CAs. The N-terminal part of an orthologous enzyme from the pathogenic yeast Candida parapsilosis contains a KR motif, which is a potential target for subtilisin-like processing proteinases. Deleting the first 48 amino acids of CaNce103p removes the homologous position, although CaNce103p does not have a $\mathrm{KR}$ motif in its $\mathrm{N}$-terminal part.

To obtain maximal protein yield, we optimized culture conditions including temperature $\left(20-37^{\circ} \mathrm{C}\right)$, cultivation time post-induction $(4-20 \mathrm{~h})$ and IPTG concentration $(0.2-1.0 \mathrm{mM})$. The highest yields of soluble CaNce103p, $\Delta 29 \_C a N c e 103 p, \Delta 48 \_C a N c e 103 p$ and $\Delta 61 \_C a N c e 103 p$ were obtained $24 \mathrm{~h}$ post-induction with $0.4 \mathrm{mM}$ IPTG with cultivation at $20^{\circ} \mathrm{C}$. The presence of the disulfide bond-reducing reagent $\beta$-mercaptoethanol was necessary 


\begin{tabular}{|c|c|}
\hline \multirow{3}{*}{$\begin{array}{l}\text { CFSSP CaNce103p } \\
\text { X-ray } \triangle 29 \_C a N c e 103 p\end{array}$} & $\Delta 48 \_C a N c e 103 p \quad \Delta 61 \_C a N ̦ c e 103 p$ \\
\hline & 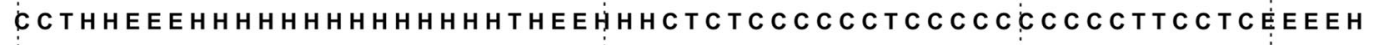 \\
\hline & $\begin{array}{llll} & & & \\
20 & 30 & 40 & 50\end{array}$ \\
\hline CaNce103p & MGRENI LKYQLEHDHESDLVTEKDQSLLLDNNNNLNGMNNTIRTHPVRVSSGNH NNF P TLS S ES \\
\hline CpNce103p & MGRENILHYLQEHN . . . . . . . ETDKELEFDAKNGSQQSKNEIEI PQFKRKVT|SH|SNFPFTLSPDS \\
\hline $\begin{array}{l}\text { CAS1 } \\
\text { ScNce103p }\end{array}$ & 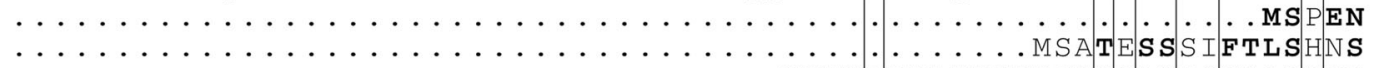 \\
\hline $\begin{array}{l}\text { Can2 } \\
\text { consensus }>50\end{array}$ & 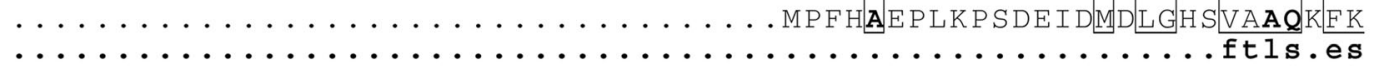 \\
\hline CFSSP CaNce103p & 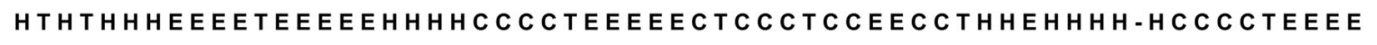 \\
\hline X-ray $\Delta 29 \_C a N c e 103 p$ & 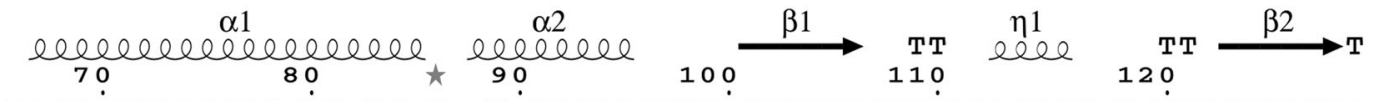 \\
\hline $\begin{array}{l}\text { CaNce103p } \\
\text { CpNce103p } \\
\text { CAS1 } \\
\text { ScNce103p } \\
\text { Can2 } \\
\text { consensus }>50\end{array}$ & 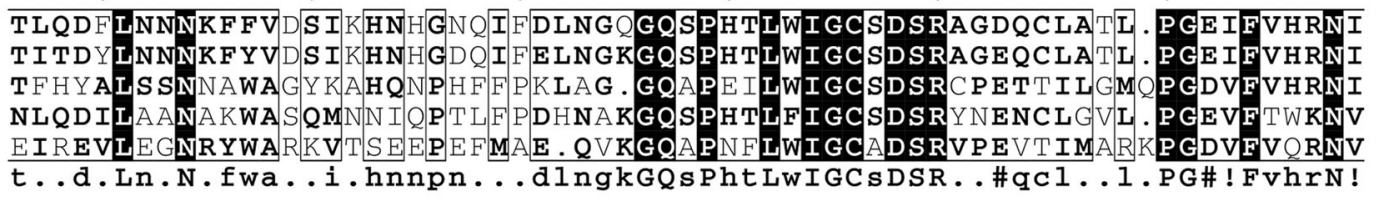 \\
\hline CFSSP CaNce103p & 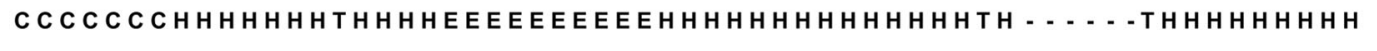 \\
\hline X-ray $\triangle 29 \_$CaNce 103p & 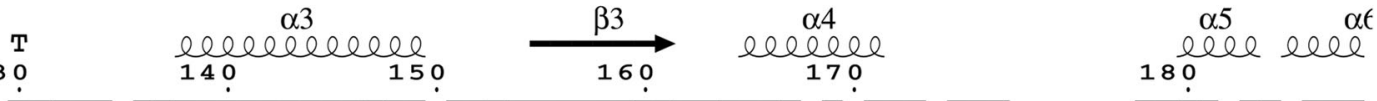 \\
\hline $\begin{array}{l}\text { CaNce103p } \\
\text { CpNce103p } \\
\text { CAS1 } \\
\text { ScNce103p } \\
\text { Can2 } \\
\text { consensus }>50\end{array}$ &  \\
\hline CFSSP CaNce103p & 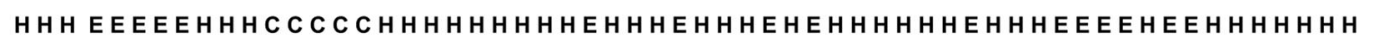 \\
\hline X-ray $\triangle 29 \_$CaNce103p & 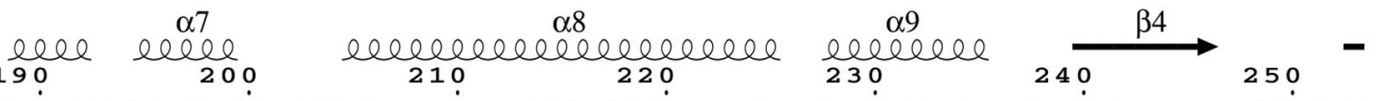 \\
\hline $\begin{array}{l}\text { CaNce103p } \\
\text { CpNce103p } \\
\text { CAS1 } \\
\text { ScNce103p } \\
\text { Can2 } \\
\text { consensus }>50\end{array}$ & 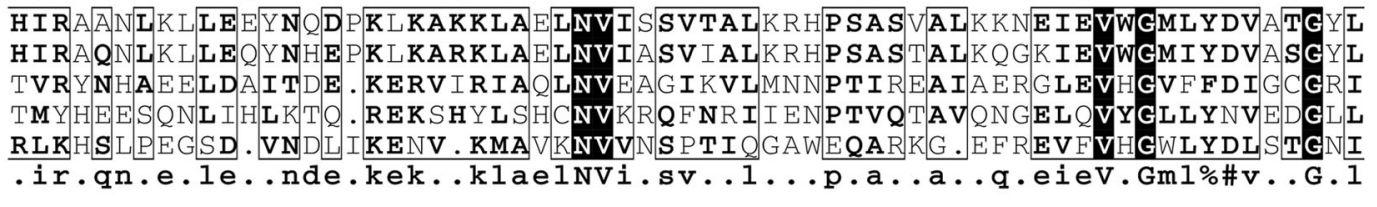 \\
\hline $\begin{array}{l}\text { CFSSP CaNce103p } \\
\text { X-ray } \triangle 29 \_C a N c e 103 p\end{array}$ & 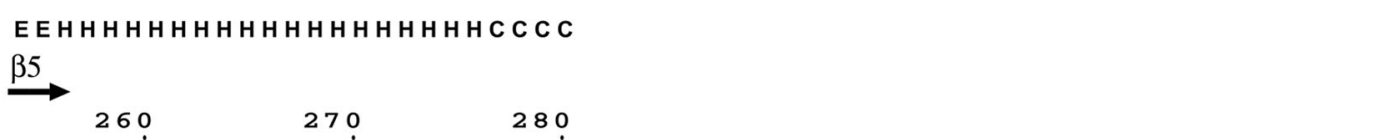 \\
\hline $\begin{array}{l}\text { CaNce103p } \\
\text { CpNce103p } \\
\text { CAS1 } \\
\text { ScNce103p } \\
\text { Can2 } \\
\text { consensus }>50\end{array}$ &  \\
\hline $\begin{array}{l}\text { Fig. } 1 \text { Multiple alignme } \\
\text { sequence multialignmer } \\
\text { (ScNce103, Swiss-Prot: } \mathrm{P} \\
\text { secondary structure regi } \\
\text { amino acid residues, res } \\
\text { (strands). The black arro } \\
\text { multialignment was per }\end{array}$ & $\begin{array}{l}\text { ent of fungal } \beta \text {-CAs and secondary structure prediction of CaNce103p. Secondary structure prediction of CaNce103p and } \\
\text { ent of CaNce103p and CAs from Candida parapsilosis, (CpNce103p, CGDID: CAL0000147197), Saccharomyces cerevisiae } \\
\text { P53615), Sordaria macrospora (CAS1, Swiss-Prot: C1L335), Cryptococcus neoformans (Can2, EMBL: Q314V7). The predicted } \\
\text { gions are indicated as follows: H-Helix, E-Sheet, T-Turn, C-Coil. Black and gray backgrounds denote identical and similar } \\
\text { spectively. Secondary structural elements (X-ray CaNce103p) found in } \triangle 29 \text { CaNce103p are shown as helices and arrows } \\
\text { ows indicate sites of truncation. All sequences were obtained from NCBI databases. Prediction of secondary structure and } \\
\text { rformed using the programs CFSSP [16], MultAlin [28] and ESPript [29] }\end{array}$ \\
\hline
\end{tabular}






to keep the protein in a soluble state during the purification process. All CaNce103p variants were purified (Fig. 2a), with average yields of $12-23 \mathrm{mg}$ purified protein per liter of culture for CaNce103p, $\Delta 29 \_$CaNce103p and $\Delta 48 \_$CaNce103p and 2-8 mg/L for $\Delta 61 \_C a N c e 103 p$.

The activity of full-length and truncated versions of CaNce103p detected using the stop-flow $\mathrm{pH} /$ dye indicator method [15] (Fig. 3) indicated that truncation by 29 and 48 amino acids did not cause differences in the enzyme activity in comparison with the wild-type full-length CaNce103p. Truncation by 61 amino acids rendered the enzyme inactive. The reaction in presence of $\Delta 61 \_$CaNce103p has a similar rate as the spontaneous hydration of $\mathrm{CO}_{2}$. The activity detection also confirmed that $\beta$-Mercaptoethanol does not negatively influence the enzyme activity.

\section{Assessment of the oligomeric structure of $\Delta 29 \_$CaNce103p}

Structures of fungal CAs solved to date indicate that these oligomeric enzymes are composed of an even number of identical subunits. We determined the oligomeric state of CaNce103p variants using size-exclusion chromatography. $\Delta 29 \_$CaNce103p formed tetramers (Fig. 3b), which was the highest-order oligomer observed in this study. $\Delta 29 \_C a N c e 103 p$ was the only version present as a monomer, dimer and tetramer under our experimental conditions. WT_CaNce103p occurred only as a dimer and tetramer. 448 CaNce103p occurred only as a monomer and a precipitate; $\Delta 61 \_$CaNce103p was present only as a precipitate. These findings suggest the importance of the $\mathrm{N}$-terminus for folding and oligomerization of CaNce103p.

\section{Protein crystallization}

Protein crystallization was facilitated by removal of the first 29 amino acids. Our attempts to crystallize full-length CaNce103p or the variants truncated by 48 or 61 residues were unsuccessful. WT_CaNce103p, 448 CaNce103p and

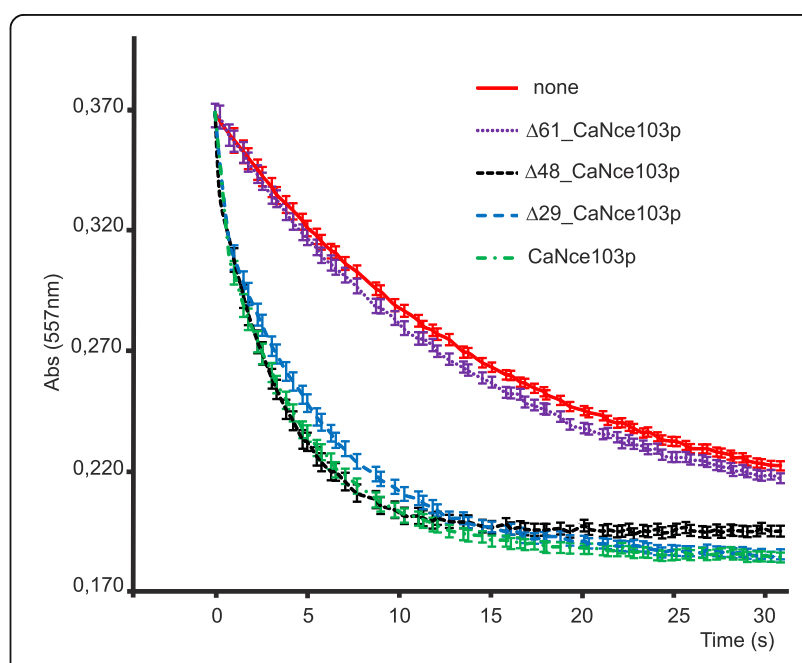

Fig. 3 Activity assays of full-lengths and truncated versions of CaNce103p. Hydration of $\mathrm{CO}_{2}$ catalyzed by carbonic anhydrase was measured as described in the Methods. The rates of reactions catalyzed by full-length CaNce103p and its truncated versions $\Delta 61$ CaNce103p, $\Delta 48$ _CaNce103p, $\Delta 29$ _CaNce103p were compared to the rate of spontaneous $\mathrm{CO}_{2}$ hydration without enzyme addition 
$\Delta 61$ CaNce103p formed precipitates or very small crystals with skin on the drop. Repeated unsuccessful attempts in a variety of crystallization conditions resulted in our decision to focus on $\Delta 29_{-}$CaNce103p. Purified $\Delta 29_{-}$CaNce103p was enzymatically active and crystallized in the form of needles belonging to the Space Group $P 2_{1} 2_{1} 2_{1}$ (Tab. 2), which allowed determination of the structure at $2.2 \AA$ resolution.

\section{Overall architecture}

The overall structure of CaNce103 is similar to that of CAS1, a $\beta$-CA from the plant fungal pathogen Sordaria macrospora [8]. It also resembles structures of $\beta$-CAs from red algae [17] and bacteria including Escherichia coli, Vibrio cholerae and Haemophilus influenzae [18-20]. CaNce103 is a complex of four identical subunits organized as a dimer of dimers, in which the dimerization and tetramerization surfaces are mutually perpendicular (Fig. 4a). The subunits in each dimer are interlocked by their N-terminal arms, consisting of two perpendicular helices stretched from the rest of the molecule over the neighboring subunit (Fig. 4b, c). Each monomer provides more than 90 residues to make contact with its dimerization partner, creating an interface of $3458 \AA^{2}$. We calculated the interaction energy stabilizing the dimer to be $-48.8 \mathrm{kcal} / \mathrm{mol}$. Association of two dimers in a tetramer is not as strong; it relies on 33 residues forming an interface of $996 \AA^{2}$. The tetramer is stabilized by an interaction energy of $-11.2 \mathrm{kcal} / \mathrm{mol}$.

The central part of each monomeric subunit is formed by a $\beta$-sheet consisting of four parallel strands and one antiparallel strand. This conserved $\beta$-structure is flanked on both sides by $\alpha$-helices. The $\mathrm{C}$-terminal part adjacent to the $\beta$-sheet domain is mostly helical. Each monomer contains one zinc atom located in the active site at the bottom of a narrow tunnel, similarly as in ScNce103p [15].

While $\Delta 29_{-}$CaNce103p was the only variant that successfully crystallized, the solved structure corresponds to CaNce103p lacking the first 60 amino acids.

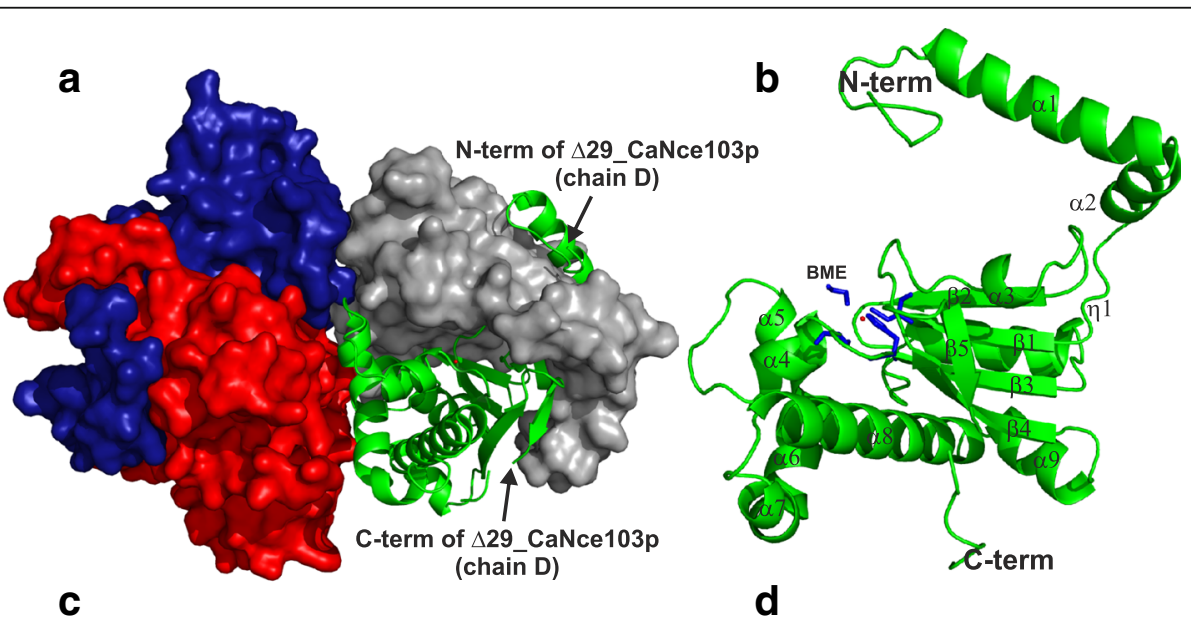

$\mathrm{N}$-term of $\triangle 29 \_$CaNce103p

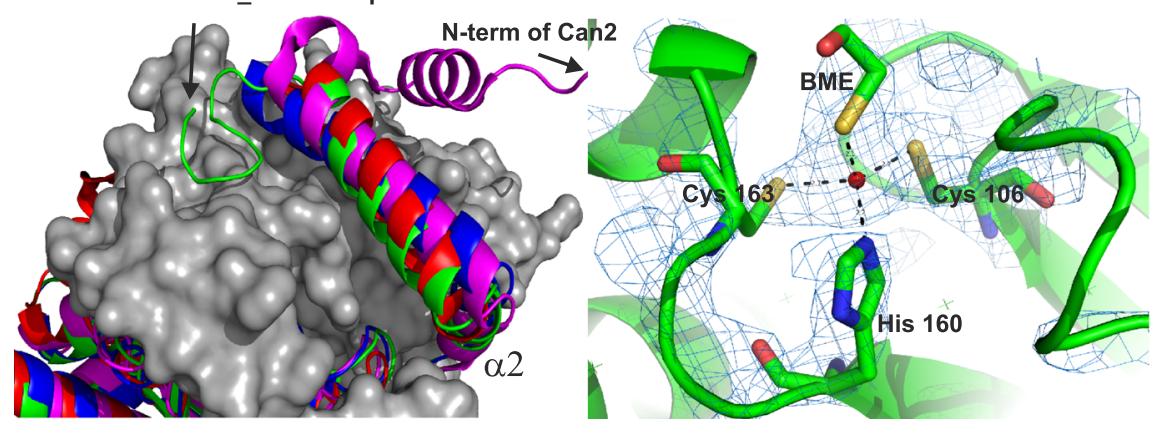

Fig. 4 Crystal structures of carbonic anhydrase $\Delta 29 \_C a N c e 103 p$. (a) Overall structure of $\Delta 29 \_C a N c e 103 p$ illustrating the tetrameric assembly. The tetramer is shown with chains A, B, C (red, blue, cyan) in surface representation and chain D (green) in cartoon representation. (b) $\Delta 29$ CaNce103p monomer. Secondary structure elements are labeled, and the positions of the $\mathrm{N}$ - and C-terminus are indicated. The $\mathrm{Zn}^{2+}$ ions are shown as red spheres. Coordinating His160, Cys106, Cys163 and B-mercaptoethanol (blue sticks) are only shown for the D chain. (c) Close-up view of superposition of the N-terminal arms of $\Delta 29$ _CaNce103p (green), ScNce103 (red), CAS1 (blue) and Can2 (magenta). The first two conserved a-helices (a1 and a2) are shown in cartoon representation. The C-terminal subdomain of the second molecule of $\Delta 29$ _CaNce103p in the asymmetric unit is shown in surface representation (gray). (d) Detailed structure of the active site in stick representation. Numbers indicate distances in $\AA$ for the contacts, shown as black dashed lines. The $2 \mathrm{~F}_{\mathrm{o}}-\mathrm{F}_{\mathrm{c}}$ electron-density map is contoured at $2.0 \sigma$ in blue 
This indicates the high flexibility of the $\mathrm{N}$-terminal part of the enzyme.

\section{CaNce103p active site}

The active site of $\Delta 29$ CaNce103p is formed by the catalytic $\mathrm{Zn}^{2+}$ coordinated by $\mathrm{S} \gamma$ atom of Cys 106, Nع2 atom of His 160 and Sy atom of Cys 163 located $2.3 \AA$ from the acceptor atom. According to these data, CaNce103p appears to be a member of the type I $\beta$-CAs, the active sites of which are typically formed by two cysteines, one histidine and a fourth ligand-usually water, acetic acid or acetate ion [7]. However, in the present structure, a molecule of $\beta$-mercaptoethanol originating from the crystallization buffer fills the fourth position (Fig. 4d).

The zinc coordination sphere is located near the dimer interface. Two of the residues contributing to the zinc coordination sphere are located at the tips of $\beta$-sheets (Cys 106 at $\beta 1$ and His 160 at $\beta 3$ ). Cys 163 is located outside of the $\beta$-sheet core. The catalytic site is surrounded by amino acids located between the $\alpha 2$ and $\alpha 4$ helices of the contributing monomer units (Figs. 1 and 5a). The contributing residues, most of which are hydrophobic (monomer providing zinc ion ligands: Ile 129, Gly 165; neighboring monomer: Phe 146, Leu 151), create a narrow tunnel (Fig. 4b), which serves as the only point of entry to the positively charged active site (Fig. 5d). The tunnel's shape and openness may be regulated by the Arg 111 - Asp 163 salt bridge that also contributes to formation of the active site cavity. This salt bridge may function as a $\mathrm{pH}$-dependent regulator of the catalytic activity of $\Delta 29$ _CaNce103p [21].

\section{Comparison of CaNce103p to other fungal carbonic anhydrases}

We aligned the crystal structure of $\Delta 29$ CaNce103p with other known $\beta$-CA structures from Cryptococcus neoformans (Can2; PDB code: 2W3N), Saccharomyces cerevisiae (ScNce103p; PDB code: 3EYX) and Sordaria macrospora (CAS1; PDB code: 4O1J). The alignment revealed very high similarity among these homologs. The monomer subunits of all structures are nearly identical, although significant differences occur in the N-terminal part. Of the CAs characterized to date, ScNce103p shares the highest sequence homology with $\Delta 29+\mathrm{CaN}-$ ce103p (Fig. 1). At the overall structural level, however, $\Delta 29+C a N c e 103 p$ is more closely related to CAS1, which also forms a tetramer. The root mean square deviation (RMSD) for the superposition of $142 \mathrm{C} \alpha$ atoms of these proteins is $0.7 \AA$. CAs from S. cerevisiae and C. neoformans form dimers, and RMSD values for superposition of ScNce103p and Can2 with CaNce103p are $1.2 \AA$ for 124 C $\alpha$ pairs and $1.1 \AA$ for $132 \mathrm{C} \alpha$ pairs, respectively.

The N-terminal part of $\Delta 29$ CaNce103p resembles those of CAS1 and ScNce103p, while the Can2 structure includes an additional helix. However, there are similarities in the substrate tunnel region of the Can2 and $\Delta 29+C a N c e 103 p$ structures. The substrate tunnels have similar shapes and orientations (Fig. 5b), although the middle part of the $\Delta 29+C a N c e 103 p$ substrate tunnel is rather narrow compared to those of other fungal CAs (Fig. 5c). We observed the most pronounced differences in shape and proportion of the substrate tunnel when comparing the $\Delta 29+\mathrm{CaN}$ ce103p and ScNce103p structures, which interestingly share the highest sequence homology. The active site structure and overall structure of $\Delta 29+C a N c e 103 p$ are nearly identical to those of CAS1.

\section{Discussion}

CAs are being investigated as drug targets and as potential components of carbon sequestration systems to alleviate increasing concentrations of atmospheric $\mathrm{CO}_{2}$ [2] . The fungal CA structure presented here is the sixth that has been solved to date, joining structures of CAs from Aspergillus oryzae, Cryptococcus neoformans, Saccharomyces cerevisiae and two CAs from Sordaria macrospora. The latter display the highest structural similarity to CaNce103p; one, CAS1, was used as a search model for CaNce103p structure determination. Interestingly, $S$. macrospora is the only fungus investigated to date that can survive in atmospheric air in the absence of a functional CA [8]. In C. albicans and S. cerevisiae, Nce103p is dispensable only in high $\mathrm{CO}_{2}$ concentrations.

Human CAs are structurally distant from yeast CAs. $\beta$-CAs do not occur in humans, and therefore may serve as a convenient target for antifungal drugs. However, currently available yeast CA inhibitors lack sufficient selectivity. Characterizing the structure of Nce103p may lead to design of more selective and potent inhibitors, which may have applications as surface disinfectants.

Unlike the orthologous enzyme from baker's yeast, CaNce103p was found to be a tetramer composed of two dimers. Dimerization is mediated by $\mathrm{N}$-terminal helices from each subunit, formed by amino acids 66-83 and 86-94. N-terminal truncation was necessary to obtain crystals, suggesting that the start of the $\mathrm{N}$-terminal domain is likely flexible and less structured. CaNce103p crystallization required removal of the first 29 residues, while truncation by 13 residues was sufficient for ScNce103p to crystallize.

The segment encompassing residues 30-48 appears to play an important role in multimerization of CaNce103p subunits, as the variant lacking the first 48 amino acids occurred only in monomeric form. However, the conformation of this segment remains unclear because the first 54 amino acids of CaNce103p were not visible in the crystal structure. Interestingly, residues 263-281, which form the end of the CaNce103p C-terminus, also were not visible in our structure. The C-terminal part of CaNce103p is longer than that of the orthologous 
a

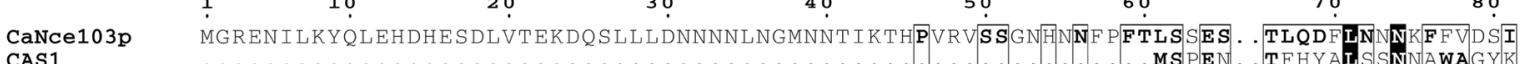
$1 \quad 10 \quad 20 \quad 30 \quad 40$

\section{0}

60

80

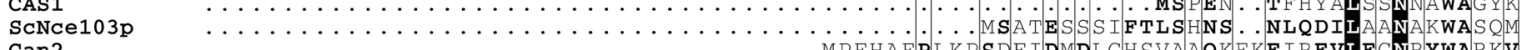

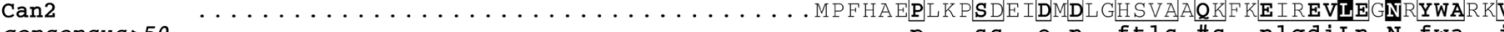

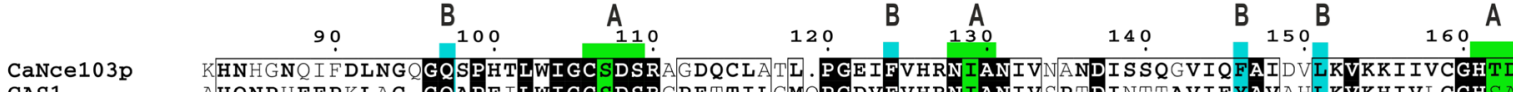

CAS1 AHONPHFFPKLAG.GQAPEILWIGCSDSRCPETTILGM PGDVFVHRNIANIVSPTDINTTAVIEYAVAHLKVKHIVLCGHS

SCNC103p NNIOPTLFPDHNAKGOSPHTLFIGCSDSRYNENCLGVL.PGEVFTWKNVANICHSEDLTLKATLEFAIICLKVNKVIICGHTD

SCNCE103p No N

$\begin{array}{ll}\text { Can2 } & \text { TSEEPEFMAE.QVKGQAPNFLWIGCADSRVPEVTIMARKPGDVFVQRNVANQF REDDSSQALLNYAIMNVGVTHVMVVGHTG } \\ \text { consensus }>50 & \text {.hnnpnffpdlngkGQaPetLwIGCSDSR.p\#qCil.1.PG\#!FvhrN!ANiv.peDissqavi\#\%A!..1kVkh!ivcGHtd }\end{array}$ A

$\begin{array}{llllllll} & 170 & 180 & 190 & 200 & 210 & 220 & 230\end{array}$

CAS1 CGG

A

CGGCIAAFDOPLPTEENPGGTP Y DDI DTMYHEESQNLI HLK. TQREKSHYLSHCNVKRQFNRI IENPTVQTAVQNGELQ

consensus>50 CGGi.aalsd.rig.....gvLd.yLnpi.tirhnn.eeld...dekek.iklaelnVi.svtvl.nnptir.aigereie

$$
\begin{array}{llll}
250 & 260 & 270 & 280
\end{array}
$$

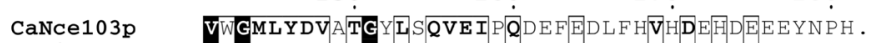

CAS1 VHGVFFDIG CGRIKELGCGTAHKSSSTISGDHVVRGKHGQLVFGQDGEAEIAAÄQ

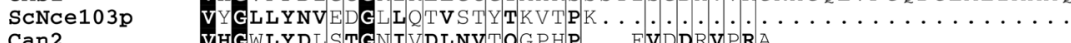

Can2 sus $>50$ VhGm $1 \%$ v

b

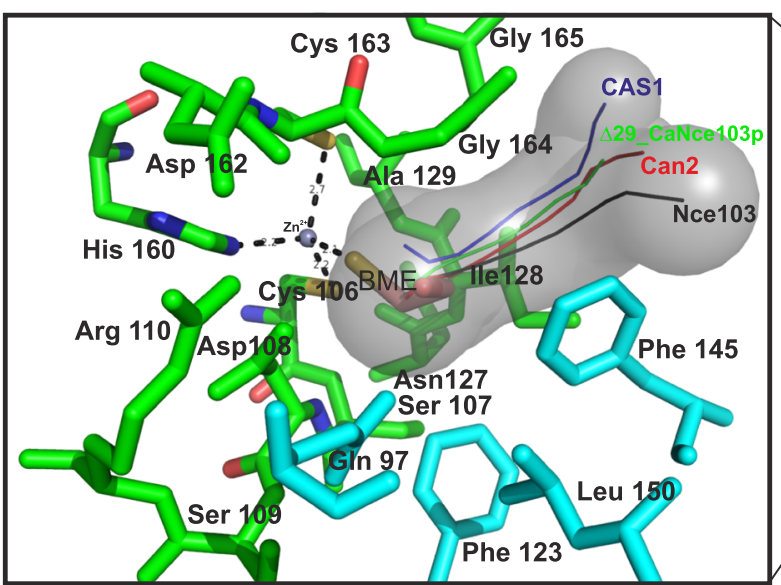

C

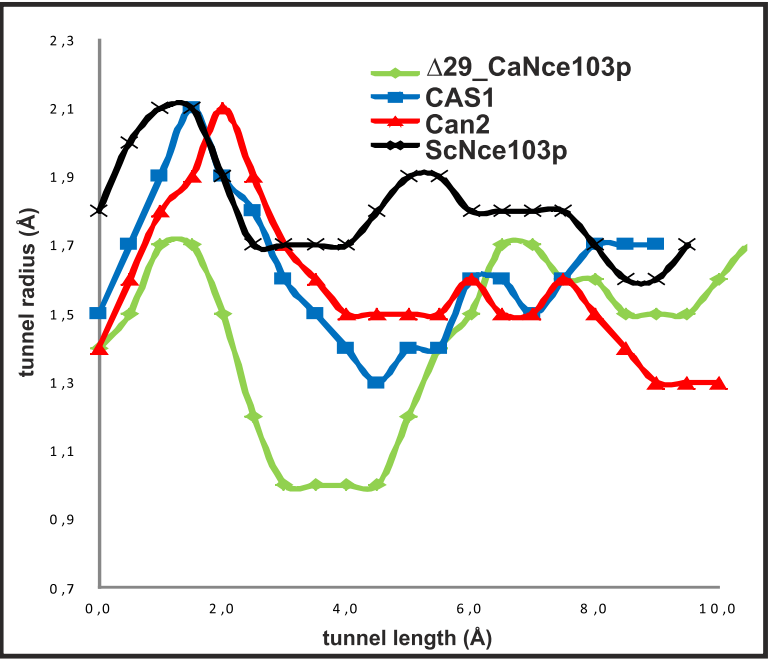

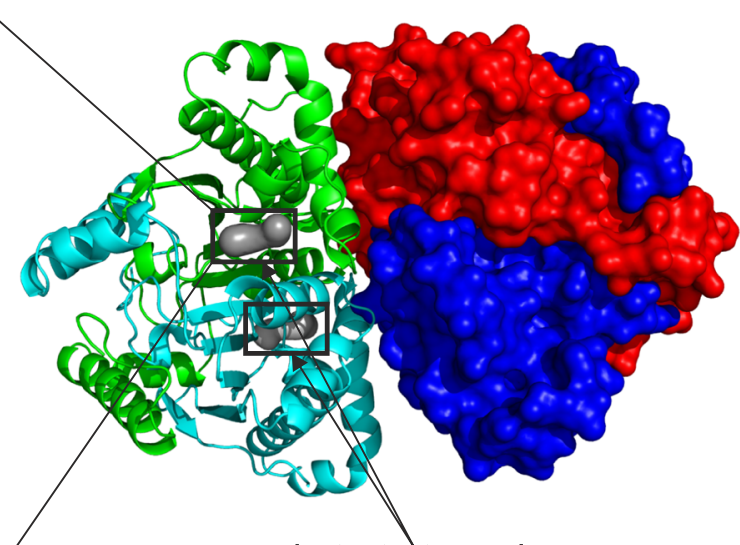

substrate tunnels

d



Fig. 5 (See legend on next page.) 
(See figure on previous page.)

Fig. 5 The substrate tunnels of $\Delta 29 \_$CaNce103p, ScNce103, CAS1 and Can2. a) Sequence alignment of $\Delta 29$ _ CaNce103p, ScNce103, CAS1 and Can2. Active site residues are indicated by asterisks. The residues forming the substrate tunnels are colored as follows: green, subunit A; cyan, subunit B. Multialignment was performed using the program MultiAlin [27]. b) Superposition of the simulated substrate tunnels of $\Delta 29$ CaNce103p, ScNce103, CAS1 and Can2. On the left side is a close-up view of the tunnels. On the right is the overall tetrameric structure of $\Delta 29$ CaNce103p with the substrate tunnels colored gray. Subunit A is green and subunit B is cyan. The tunnel profiles of each of the CAs are represented by colored lines: green (A29_CaNce103p), black (ScNce103), red (Can2) and blue (CAS1). c) Line graphs of the substrate tunnel profiles. Simulations of the substrate tunnels were performed using the program CAVER [30]. d) Close-up view of the entrance of the $\Delta 29$ _CaNce103 active site. The image shows the solvent accessible surface colored by electrostatic potential (red for negative, blue for positive)

ScNce103p. Non-conserved, flexible termini might play a role in interactions between CAs and other molecules, calling for further investigation.

The active site of $\Delta 29+C a N c e 103 p$ does not differ substantially from those of other type I $\beta$-CAs. The only distinct feature was the molecule of $\beta$-mercaptoethanol coordinating the catalytic zinc ion. $\beta$-Mercaptoethanol was an important component of all the buffers used during $\Delta 29$ CaNce103p purification, and the presence of a reducing agent appears to be essential for the protein's stability and solubility. The active site is located at the bottom of the substrate tunnel, the size of which differs from substrate tunnels of other structurally characterized fungal CAs.

Currently available data suggest that CAs from C. albicans and S. cerevisiae are likely to play a similar physiological role. They are also close homologs at the amino acid sequence level. On the structural level, however, ScNce103p and $\Delta 29$ _CaNce103p differ.

\section{Conclusions}

In the present work, the crystal structure of N-terminally truncated CA from the pathogenic yeast Candida albicans ( $\Delta 29$-CaNce103p) was determined at $2.2 \AA$ resolution. It is the sixth fungal $\mathrm{CA}$ to be structurally characterized by X-ray crystallography. To obtain crystals, truncation of the $29 \mathrm{~N}$-terminal amino acids was necessary. $\Delta 29$ CaNce103p forms a homotetramer organized as a dimer of dimers. Although the overall molecular architecture and the active site structure of $\Delta 29 \_C a N c e 103 p$ share similarities with other $\beta$-class $\mathrm{CAs}$, the $\mathrm{N}$ - and $\mathrm{C}$-terminal parts of the monomeric subunits and the substrate tunnel differ. The structure of $\Delta 29 \_$CaNce103p will aid the design of inhibitors that potentially could be incorporated into antimycotic surface disinfectants.

\section{Methods}

\section{Cloning and expression of CaNce103p}

Genomic DNA was isolated from C. albicans strain HE109 obtained from the mycological collection of the Faculty of Medicine, Palacky University, Olomouc, Czech Republic. The gene NCE103 and its truncated versions were amplified using the primers listed in the Table 1 and inserted using the InFusion HD Cloning Kit
(Clontech) into a pET22b vector linearized with NdeI and XhoI restriction enzymes. All DNA segments resulting from PCR were verified by sequencing. The resulting expression vectors were transformed into Escherichia coli BL23(DE3). Bacteria were cultivated in Luria-Bertani medium containing $50 \mu \mathrm{g} / \mathrm{ml}$ ampicillin and $0.5 \mathrm{mM}$ $\mathrm{ZnSO}_{4}$ in a rotation shaker at $37^{\circ} \mathrm{C}$ [8]. When $\mathrm{OD}_{600 \mathrm{~nm}}$ reached 0.8 , production of CaNce103p was induced by addition of IPTG to a final concentration of $1 \mathrm{mM}$. The culture was then incubated overnight at $20{ }^{\circ} \mathrm{C}$, and the cells were harvested by centrifugation at $4000 \mathrm{~g}$ for $10 \mathrm{~min}$. The cells were resuspended in $10 \mathrm{mM}$ Tris- $\mathrm{Cl}$, $\mathrm{pH} 8$, containing $0.5 \mathrm{M} \mathrm{NaCl}$, and disintegrated using an EmulsiFlex-C3 homogenizer. The cell lysate was centrifuged at $15,000 \mathrm{~g}$ for $15 \mathrm{~min}$ at $4{ }^{\circ} \mathrm{C}$. CaNce103p was present in the supernatant and was purified using a HiTrap Ni column (GE Healthcare) equilibrated in $10 \mathrm{mM}$ Tris-Cl, $\mathrm{pH} 8,0.5 \mathrm{M} \mathrm{NaCl}$. Proteins were eluted with a $0-0.5 \mathrm{M}$ imidazole gradient. The eluate was collected in test tubes containing $20 \mathrm{mM}$ Tris- $\mathrm{Cl}, \mathrm{pH} 8$, supplemented with $40 \mathrm{mM} \beta$-mercaptoethanol, $400 \mathrm{mM}$ $\mathrm{NaCl}$ and $20 \%$ glycerol. The ratio of eluate to buffer in the test tubes was 1:1. Selected fractions were pooled and dialyzed against $10 \mathrm{mM}$ Tris- $\mathrm{Cl}, \mathrm{pH} 8$, containing $20 \mathrm{mM} \beta$-mercaptoethanol, and $10 \%$ glycerol. The final purification step was anion-exchange chromatography on a MonoQ column equilibrated in $10 \mathrm{mM}$ Tris- $\mathrm{Cl}$, $\mathrm{pH}$ 8, $20 \mathrm{mM} \beta$-mercaptoethanol, 10\% glycerol. Proteins were eluted using a $0-1 \mathrm{M} \mathrm{NaCl}$ gradient. The efficiency of purification was analyzed using SDS-PAGE, Western blotting and activity assays. The amino acid sequences of the obtained proteins were verified by $\mathrm{N}$-terminal protein sequencing and MS mass-fingerprinting analysis.

\section{Enzyme activity}

Carbonic anhydrase activity was tested using a colorimetric assay to measure $\mathrm{CO}_{2}$ hydration. Samples of purified proteins were added to final concentration of $0.005 \mathrm{mg} / \mathrm{ml}$ to $5 \mathrm{mM}$ HEPES, pH 7.5, containing $20 \mathrm{mM} \mathrm{Na}_{2} \mathrm{SO}_{4}$ and $200 \mu \mathrm{M}$ phenol red. This suspension was mixed in a 1:1 volume ratio with $3.2 \mathrm{mM} \mathrm{CO}_{2}$ solution using a stopped flow device (Rapid Mix accessory RX2000 from Applied Photophysics), and the reaction was monitored using a spectrophotometer (Unicam UV-510 from Thermo Spectronic). 
Table 1 Primers used in this study

\begin{tabular}{|c|c|c|c|}
\hline Construct & Primer name & Sequence & Restriction site \\
\hline \multirow[t]{2}{*}{$\overline{\mathrm{WT}}$} & WT_CaNCE103 Nde I F & AAGGAGATATACATATGATGGGTAGAGAAAATATTITGAA & Ndel \\
\hline & $\Delta 29 / \Delta 48 / \Delta 61 \_C a N C E 103$ Xho I R & GGTGGTGGTGCTCGAGTCAATGAGGGTTATATTCTTCTTC & Xhol \\
\hline \multirow[t]{2}{*}{$\Delta 29$} & $\Delta 29 \_C a N C E 103$ Nde I F & AAGGAGATATACATATGGATAATAATAACAACCTAAACGG & Ndel \\
\hline & $\Delta 29 / \Delta 48 / \Delta 61 \_C a N C E 103$ Xho I R & GGTGGTGGTGCTCGAGTCAATGAGGGTTATATTCTTCTTC & Xhol \\
\hline \multirow[t]{2}{*}{$\Delta 48$} & $\Delta 48 \_C a N C E 103$ Nde I F & AAGGAGATATACATATGGTTAGTTCAGGAAATCATAATAAT & Ndel \\
\hline & $\Delta 29 / \Delta 48 / \Delta 61 \_C a N C E 103$ Xho I R & GGTGGTGGTGCTCGAGTCAATGAGGGTTATATTCTTCTTC & Xhol \\
\hline \multirow[t]{2}{*}{$\Delta 61$} & D61_CaNCE103 Nde I F & AAGGAGATATACATATGTCTTCAGAATCTACATTACAAGATTT & Ndel \\
\hline & $\Delta 29 / \Delta 48 / \Delta 61 \_C a N C E 103$ Xho I R & GGTGGTGGTGCTCGAGTCAATGAGGGTTATATTCTTCTTC & Xhol \\
\hline
\end{tabular}

Absorbance at $557 \mathrm{~nm}$ was recorded for $30 \mathrm{~s}$ but only the first second was used for the activity analysis. Control reactions were performed in the absence of enzyme.

\section{Size exclusion chromatography}

To determine the oligomeric state of carbonic anhydrases, size exclusion chromatography was performed using an HR200 Increase column equilibrated in $10 \mathrm{mM}$ Tris- $\mathrm{Cl}, \mathrm{pH}$ 8, $20 \mathrm{mM} \beta$-mercaptoethanol. The flow rate was adjusted to $0.5 \mathrm{ml} / \mathrm{min}$, and the column was calibrated using the Gel Filtration Markers Kit for molecular weights 12,000-200,000 from Sigma Aldrich.

\section{Crystallization, data collection and structure \\ determination}

CaNce103p and its truncated versions $(\Delta 29+C a N c e 103 p$, $\Delta 48$ CaNce103p, $\Delta 61$ CaNce103p) were concentrated using an Amicon Ultra-30 ultrafiltration device (Millipore) to $10 \mathrm{mg} / \mathrm{ml}$. Initial crystallization trials were performed with the help of a Gryphon crystallization workstation (Art Robbins Instruments) by the sitting drop vapor diffusion method at $18{ }^{\circ} \mathrm{C}$ in 96-well plates; $0.2 \mu \mathrm{l}$ protein solution was mixed with $0.2 \mu \mathrm{l}$ well solution and the mixture was equilibrated over a $200 \mu \mathrm{l}$ reservoir solution. PEGs Suite I and JCSG Core I Suite (QIAGEN) were used for the crystallization condition screen. Initial microcrystals of $\Delta 29 \_$CaNce103p appeared in several days under the following conditions: $0.2 \mathrm{M}$ ammonium acetate or $0.2 \mathrm{M}$ magnesium chloride, $0.1 \mathrm{M}$ Bis-Tris, pH 5.5, 25\% (w/v) PEG 3350 or $45 \%(\mathrm{w} / \mathrm{v})$ MPD. Further subsequent optimization of crystallization conditions involved changing to the hanging drop mode, which was performed in NeXtal plates (Qiagen) for easy crystal manipulation. Final crystals were obtained by mixing $3 \mu \mathrm{l} \Delta 29$ CaNce103p with $1 \mu \mathrm{l}$ reservoir solution composed of $0.1 \mathrm{M}$ ammonium acetate, $\mathrm{pH} 5.5,25 \%$ PEG 3350.

For data collection, the crystal was frozen in liquid nitrogen. For cryoprotection, the crystals were soaked for $10 \mathrm{~s}$ in the corresponding reservoir solution supplemented with $25 \%(v / v)$ glycerol. Diffraction data for
Table 2 Crystal data and diffraction data collection and refinement statistics

\begin{tabular}{|c|c|}
\hline \multicolumn{2}{|l|}{ Data-collection statistics } \\
\hline Wavelength $(\AA)$ & 0.9184 \\
\hline Space group & $P 2,2,2$, \\
\hline Unit-cell parameters $\left(\AA{ }^{\circ}{ }^{\circ}\right)$ & $\begin{array}{l}a=69.37, b=90.29, c= \\
167.12, \\
a=90.0, \beta=90.0, \gamma=90.0\end{array}$ \\
\hline No. of molecules in asymmetric unit & 4 \\
\hline Resolution range $(\AA)$ & $50-2.2(2.33-2.20)$ \\
\hline No. of unique reflections & $53,038(8439)$ \\
\hline Multiplicity & $4.5(4.6)$ \\
\hline Completeness (\%) & $98.1(98.2)$ \\
\hline Rmerge† & $16.5(238.5)$ \\
\hline Average $\mid / \sigma(I)$ & $8.27(0.62)$ \\
\hline Wilson $B\left(\AA^{2}\right)$ & 49.0 \\
\hline \multicolumn{2}{|l|}{ Refinement statistics } \\
\hline Resolution range $(\AA)$ & $45.95-2.20(2.3-2.20)$ \\
\hline No. of reflections in working set & $51,601(6327)$ \\
\hline No. of reflections in test set & $1053(129)$ \\
\hline Rworkł (\%) & $24.1(40.5)$ \\
\hline Rfree§ (\%) & $27.9(43.0)$ \\
\hline Rall (\%) & 24.1 \\
\hline R.m.s.d., bond lengths ( $\AA$ ) & 0.019 \\
\hline R.m.s.d., bond angles $(\AA)$ & 1.57 \\
\hline No. of non-H atoms in asymmetric unit & 6269 \\
\hline $\begin{array}{l}\text { No. of water molecules in asymmetric } \\
\text { unit }\end{array}$ & 35 \\
\hline Mean ADP $\left(\AA^{2}\right)$ & 81.6 \\
\hline Main chain (A/B/C/D) & 76.5/75.8/92.0/82.2 \\
\hline Side chain (A/B/C/D) & 80.8/80.3/93.7/86.4 \\
\hline Water & 62.3 \\
\hline Residues in alternative conformations & 0 \\
\hline \multicolumn{2}{|l|}{ Ramachandran plot statistics } \\
\hline Residues in favoured regions (\%) & 95.7 \\
\hline Residues in allowed regions (\%) & 4.1 \\
\hline
\end{tabular}


$\Delta 29$ CaNce103p were collected to $2.2 \AA$ resolution at $100 \mathrm{~K}$ using the MX14.2 beamline at BESSY, Berlin, Germany [22]. Diffraction data were processed using the XDS suite [23, 24] using XDSAPP2.0 [25].

The structure was determined by molecular replacement using the program Molrep. $\beta$-CA from Sordaria macrospora (PDB ID: 4O1J) was used as the search model. Model refinement was carried out using the program Phenix.refine [26] from the Phenix package (version 1.9-1692) [27], and the final cycles were performed with REFMAC 5.2 from the CCP4 package. Manual building was performed using Coot. The quality of the final model was validated with the Molprobity server.

Crystal parameters, data collection and refinement statistics are summarized in Table 2. Structural representations were prepared with the program PyMOL. Atomic coordinates and experimental structure factors have been deposited in the Protein Data Bank under code 6GWU.

\section{Abbreviations \\ Can2: Carbonic anhydrase from Cryptococcus neoformans; \\ CaNce103p: Carbonic anhydrase from Candida albicans; CAs: Carbonic anhydrases; CAS1: Carbonic anhydrase from Sordaria macrospora; NCE: Non- classical export; RMSD: Root mean square deviation; ScNce103p: Carbonic anhydrase from Saccharomyces cerevisiae}

\section{Acknowledgements}

The authors would like to thank the IOCB MS facility for performing the peptide mass fingerprinting analysis, Zdeněk Voburka for N-terminal protein sequencing and Mrs. Elena Dolejší for technical assistance.

\section{Funding}

This work was supported by grant GA17-08343S from the Czech Science Foundation and NPU project LO1302 from the Ministry of Education, Czech Republic.

\section{Availability of data and materials}

Crystal parameters, data collection and refinement statistics are summarized in Table 2. Structural representations were prepared with the program PyMOL. Atomic coordinates and experimental structure factors have been deposited in the Protein Data Bank under code 6GWU.

\section{Authors' contributions \\ JD conceived and performed most of the experimental work. JB1 performed data collection, data processing, structure determination, refinement and structure function analysis of CaNce103p. JB2 participated in cloning and protein purification. SM participated in protein purification, protein crystallization and activity assays. $\mathrm{OH}$ prepared one of the vectors, helped with the study design and drafted the manuscript. IP participated in experimental design and writing the paper. All authors read and approved the final manuscript.}

\section{Ethics approval and consent to participate}

Not applicable.

\section{Consent for publication}

Not applicable.

\section{Competing interests}

The authors declare that they have no competing interests.

\section{Publisher's Note}

Springer Nature remains neutral with regard to jurisdictional claims in published maps and institutional affiliations.

\section{Author details}

'Institute of Organic Chemistry and Biochemistry of the Czech Academy of Sciences, Flemingovo náměstí 2, 16610 Prague, Czech Republic.

${ }^{2}$ Department of Biological and Biochemical Sciences, Faculty of Chemical Technology, University of Pardubice, Studentská 95, 53210 Pardubice, Czech Republic.

Received: 26 June 2018 Accepted: 2 October 2018

Published online: 26 October 2018

\section{References}

1. Koenig $\mathrm{SH}$, Brown RD. Kinetic parameters of human carbonic anhydrase $\mathrm{B}$ as determined from NMR linewidths of $13 \mathrm{C}$ in $\mathrm{CO} 2$ and $\mathrm{HCO}$ 3-. Biochem Biophys Res Commun 1973;53:624-630.

2. Boone CD, Gill S, Habibzadegan A, McKenna R. Carbonic anhydrase: an efficient enzyme with possible global implications. Int J Chem Eng. 2013; 2013:1-6.

3. Lehneck R, Pöggeler S. A matter of structure: structural comparison of fungal carbonic anhydrases. Appl Microbiol Biotechnol. 2014;98:8433-41.

4. Supuran CT. Structure and function of carbonic anhydrases. Biochem J. 2016;473:2023-32.

5. Brinkman R. The occurrence of carbonic anhydrase in lower marine animals. J Physiol. 1933;80:171-3.

6. Neish AC. Studies on chloroplasts: their chemical composition and the distribution of certain metabolites between the chloroplasts and the remainder of the leaf. Biochem J. 1939:33:300-8.

7. Rowlett RS. Structure and catalytic mechanism of the $\beta$-carbonic anhydrases. Biochim Biophys Acta. 1804;2010:362-73.

8. Lehneck R, Neumann P, Vullo D, Elleuche $S$, Supuran $C T$, Ficner $R$, et al. Crystal structures of two tetrameric $\beta$-carbonic anhydrases from the filamentous ascomycete Sordaria macrospora. FEBS J. 2014;281:1759-72.

9. Klengel T, Liang W-JJ, Chaloupka J, Ruoff C, Schröppel K, Naglik JR, et al. Fungal adenylyl cyclase integrates $\mathrm{CO} 2$ sensing with CAMP signaling and virulence. Curr Biol. 2005;15:2021-6.

10. Cleves AE, Cooper DN, Barondes SH, Kelly RB. A new pathway for protein export in Saccharomyces cerevisiae. J Cell Biol. 1996;133:1017-26.

11. Amoroso G, Morell-Avrahov L, Müller D, Klug K, Sültemeyer D. The gene NCE103 (YNL036W) from Saccharomyces cerevisiae encodes a functional carbonic anhydrase and its transcription is regulated by the concentration of inorganic carbon in the medium. Mol Microbiol. 2005;56:549-58.

12. Götz R, Gnann A, Zimmermann FK. Deletion of the carbonic anhydrase-like geneNCE103 of the yeastSaccharomyces cerevisiae causes an oxygensensitive growth defect. Yeast. 1999;15:855-64.

13. Brown AJP, Brown GD, Netea MG, NAR G. Metabolism impacts upon candida immunogenicity and pathogenicity at multiple levels. Trends Microbiol. 2014;22:614-22.

14. Cottier F, Raymond M, Kurzai O, Bolstad M, Leewattanapasuk W, JiménezLópez $C$, et al. The bZIP transcription factor Rca1p is a central regulator of a novel $\mathrm{CO}_{2}$ sensing pathway in yeast. PLoS Pathog. 2012;8:e1002485.

15. Teng Y-B, Jiang Y-L, He Y-X, He W-W, Lian F-M, Chen Y, et al. Structural insights into the substrate tunnel of Saccharomyces cerevisiae carbonic anhydrase Nce103. BMC Struct Biol. 2009;9:67.

16. Ashok Kumar T. CFSSP: Chou and Fasman Secondary Structure Prediction server. WIDE SPECTRUM: Research Journal. 2013;1(9):15-19.

17. Mitsuhashi S, Mizushima T, Yamashita E, Yamamoto M, Kumasaka T, Moriyama $\mathrm{H}$, et al. X-ray structure of beta-carbonic anhydrase from the red alga, Porphyridium purpureum, reveals a novel catalytic site for $\mathrm{CO}(2)$ hydration. J Biol Chem. 2000;275:5521-6.

18. Cronk JD, Endrizzi JA, Cronk MR, O'neill JW, Zhang KY. Crystal structure of E. coli beta-carbonic anhydrase, an enzyme with an unusual pH-dependent activity. Protein Sci. 2001;10:911-22.

19. Ferraroni M, Del Prete S, Vullo D, Capasso C, Supuran CT. Crystal structure and kinetic studies of a tetrameric type II $\beta$-carbonic anhydrase from the pathogenic bacterium Vibrio cholerae. Acta Crystallogr D Biol Crystallogr. 2015;71:2449-56.

20. Cronk JD, Rowlett RS, Zhang KYJ, Tu C, Endrizzi JA, Lee J, et al. Identification of a novel noncatalytic bicarbonate binding site in eubacterial betacarbonic anhydrase. Biochemistry. 2006;45:4351-61.

21. Suarez Covarrubias A, Larsson AM, Högbom M, Lindberg J, Bergfors T, Björkelid C, et al. Structure and function of carbonic anhydrases from Mycobacterium tuberculosis. J Biol Chem. 2005;280:18782-9. 
22. Mueller U, Darowski N, Fuchs MR, Förster R, Hellmig M, Paithankar KS, et al. Facilities for macromolecular crystallography at the Helmholtz-Zentrum Berlin. J Synchrotron Radiat. 2012;19:442-9.

23. Kabsch W. Integration, scaling, space-group assignment and postrefinement. Acta Crystallogr D Biol Crystallogr. 2010;66:133-44.

24. Kabsch W. XDS. Acta Crystallogr D Biol Crystallogr. 2010;66:125-32

25. Sparta KM, Krug M, Heinemann U, Mueller U, Weiss MS, IUCr. XDSAPP2.0. J Appl Crystallogr. 2016:49:1085-92

26. Afonine PV, Grosse-Kunstleve RW, Echols N, Headd JJ, Moriarty NW, Mustyakimov $M$, et al. Towards automated crystallographic structure refinement with phenix. refine. Acta Crystallogr D Biol Crystallogr. 2012;68:352-67.

27. Adams PD, Afonine PV, Bunkóczi G, Chen VB, Davis IW, Echols N, et al. PHENIX: a comprehensive Python-based system for macromolecular structure solution. Acta Crystallogr D Biol Crystallogr. 2010;66:213-21.

28. Corpet F. Multiple sequence alignment with hierarchical clustering. Nucleic Acids Res. 1988;16(22):10881-10890.

29. Gouet P. ESPript/ENDscript: extracting and rendering sequence and 3D information from atomic structures of proteins. Nucleic Acids Res. 2003; 31(13):3320-3323.

30. Kozlíková B, Šebestová E, Šustr V, Brezovský J, Strnad O, Daniel L, et al. CAVER Analyst 1.0: Graphic Tool for Interactive Visualization and Analysis of Tunnels and Channels in Protein Structures, Bioinformatics, 2014;30(18).

Ready to submit your research? Choose BMC and benefit from:

- fast, convenient online submission

- thorough peer review by experienced researchers in your field

- rapid publication on acceptance

- support for research data, including large and complex data types

- gold Open Access which fosters wider collaboration and increased citations

- maximum visibility for your research: over $100 \mathrm{M}$ website views per year

At BMC, research is always in progress.

Learn more biomedcentral.com/submissions 